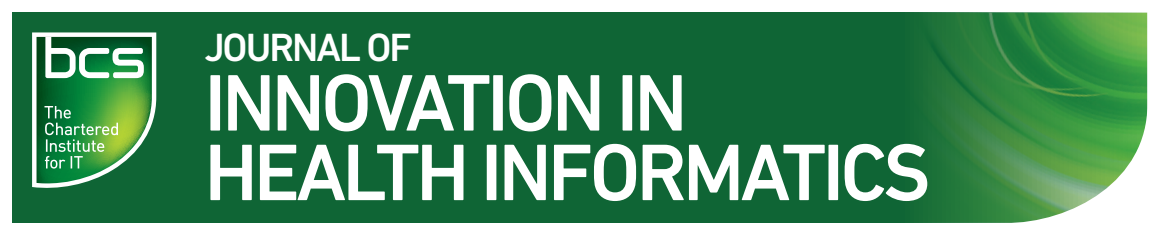

\title{
Practical applications and discussions
}

Cite this article: Sridharan S, Priestman W, Sebire NJ. Chief Information Officer team evolution in university hospitals: interaction of the three 'C's (CIO, CCIO, CRIO). J Innov Health Inform. 2018;25(2):88-91.

http://dx.doi.org/10.14236/jhi.v25i2.997

Copyright ( 2018 The Author(s). Published by BCS, The Chartered Institute for IT under Creative Commons license http://creativecommons.org/licenses/by/4.0/

Author address for correspondence: Neil J. Sebire

Digital Research, Informatics and Virtual Environment (DRIVE) Unit Department of Information Technology Great Ormond Street Hospital for Children NHS Foundation Trust London WC1N 3JH, UK

Email: neil.sebire@gosh.nhs.uk

Accepted June 2018

\section{Chief Information Officer team evolution in university hospitals: interaction of the three 'C's (CIO, CCIO, CRIO)}

\section{Shankar Sridharan}

Digital Research, Informatics and Virtual Environment (DRIVE) Unit, Great Ormond Street Hospital for Children NHS Foundation Trust, UK

\section{Ward Priestman}

Digital Research, Informatics and Virtual Environment (DRIVE) Unit, Great Ormond Street Hospital for Children NHS Foundation Trust, UK

\section{Neil J. Sebire}

Digital Research, Informatics and Virtual Environment (DRIVE) Unit, Great Ormond Street Hospital for Children NHS Foundation Trust, UK

\section{ABSTRACT}

Background The Chief Information Officer ( $\mathrm{ClO})$ and Chief Clinical Information Officer ( $\mathrm{CCIO})$ are now established senior roles in hospital practice. With increasing emphasis on optimising use of routine health data for secondary purposes and research, additional skills are required as part of the senior information officer team, particularly in academic health care institutions.

Objective To present the role of the Chief Research Information Officer (CRIO), as an emerging, and important, component of the senior information team.

Method We review recent publications describing the composition of the senior information team, including $\mathrm{ClO}$ and $\mathrm{CClO}$ roles, and discuss the development of the CRIO as a distinct component of the team, based on the published evidence and our experience.

Results The CRIO is emerging as an additional senior role in academic healthcare institutions, whose roles include leadership of the informatics strategy and optimisation of routine data collection systems for research data use, in addition to important aspects of research data governance. Such individuals should be senior clinicians with experience in informatics, in addition to having established research expertise and knowledge of research processes, governance and academic networks.

Conclusions The CRIO is emerging as a distinct senior information leadership role in conjunction with the already established positions of $\mathrm{CClO}$ and $\mathrm{ClO}$, who together, can provide optimal oversight of digital activities across the organisation.

Keywords: $\mathrm{CRIO}, \mathrm{CCIO}, \mathrm{CIO}$, clinical informatics, research, data 


\section{INTRODUCTION}

The impact of developing technologies on hospital practice has resulted in growing recognition that the collection, storage, presentation and analysis of patient and operational data represents an increasingly fundamental function of hospitals. Furthermore, research hospitals, university hospitals and academic medical centres have identified the need for an additional role in carrying out a range of medical research studies, for which having the appropriate 'digital infrastructure' and skillset is increasingly essential. For these reasons, the senior team required to ensure delivery of such digital programmes is evolving and digital infrastructure and expertise regarding research application should now be viewed as a core component of academic hospital centres, essential to adequate provision of all other services. We discuss how the Chief Information Officer (CIO) leadership team for healthcare institutions has changed with time, with particular emphasis on the emerging role of the Chief Research Information Officer (CRIO), based on published studies and evidence from our academic centre.

\section{The Chief Information Officer team}

The senior team responsible for information communications technology (ICT) within the hospital was traditionally the $\mathrm{CIO}$, a non-medically qualified professional with expertise in ICT management, whose key roles included managing all aspects of information technology (IT) resources and policy and practice development, planning, budgeting, resourcing and training. ${ }^{1-3}$ The CIO has oversight of how IT professionals and non-IT professionals should interact in the organisation and has a senior strategic role, usually at executive level, regarding things such as purchase of IT equipment, decisions on systems and delivery of the overall ICT strategy. The CIO role is a strategic position with a firm operational and technical understanding of both technology and hospital processes. The $\mathrm{ClO}$ is an essential role for all organisations and businesses, but, whilst all of the above aspects equally apply to hospitals, additional specific roles are required to support the $\mathrm{ClO}$ in a hospital setting due to the requirements of the healthcare environment, and in academic health institutions internationally, the move is towards a ' $\mathrm{C}$ ' team, of $\mathrm{ClO}$, Chief Clinical Information Officer ( $\mathrm{CCIO})$ and $\mathrm{CRIO}$ to adequately fulfil all requirements at this level.

\section{Chief Clinical Information Officer}

Whilst the $\mathrm{CIO}$ is an ICT focused technical and organisational role, the $\mathrm{CCIO}$ represents a senior healthcare role with experience and expertise of a practising clinician. The need for hospitals to appoint $\mathrm{CCIOs}$ has been established for many years in some countries, such as the USA, whilst the National Health Service (NHS) named its first National NHS CCIO in July 2016, with a remit to transform how the NHS uses digital technology specifically to improve patient care. ${ }^{4}$ The $\mathrm{CCIO}$ therefore provides clinical focus on how to best implement and benefit from digital technologies in a hospital setting and acts as a link between the $\mathrm{CIO}$ and ICT team, and the clinical teams in delivering technology into clinical areas. The $\mathrm{CIO}$ and $\mathrm{CClO}$ jointly develop optimal ways of implementing any technology within the organisation in a way that enhances clinical activities and patient care. The CCIO's main role is to improve the healthcare of patients, as well as patient experience, using information, data and digital technologies. ${ }^{5}$

However, appointing CClOs with appropriate skills and understanding remains challenging, and the general lack of clinicians with detailed ICT and technology skills (Clinical Informaticians) has been highlighted in the recent Wachter report https://www.england.nhs.uk/digitaltechnology/info-revolution/nhs-digital-academy/. ${ }^{6}$ The role of the $\mathrm{CClO}$ is now becoming established, and in the UK, the NHS Digital Academy has been launched in 2017 with the aim of developing and training the next generation of $\mathrm{CClOs} .{ }^{7}$

The main roles of the $\mathrm{CClO}$ include change management, ensuring clinical adoption and engagement in the use of technology, supporting clinical process redesign in a digital world, providing clinical focus to ICT projects such that they meet the needs of the business (in this setting, patient care and hospital operations), promoting ICT use to improve safety, quality, patient and family satisfaction, ensuring efficiency in delivery of care, integration with biomedical equipment and overall cost reduction, ensuring standardisation of clinical terminology, coding and compliance. ${ }^{8}$ In summary, CCIOs provide senior physician leadership to guide and support implementation of electronic health information systems related to the delivery of patient care, therefore being a significant role of a physician with $>10$ years clinical experience and at executive level. On-going clinical commitment is required to maintain a credible link to clinical practice to engage colleagues and experience first-hand the impact of change. Since medical diagnosis and treatments are becoming more complex, the population is aging and there are increasing financial constraints, there are opportunities to leverage digital technologies to standardise and optimise healthcare delivery. A key focus of the CCIOs therefore to ensure that digital projects maintain clinical relevance and release benefits.

\section{Chief Research Information Officer}

In some $\mathrm{CClO}$ job descriptions, in addition to all of the above, an additional line of further responsibilities are included such as integrating clinical and research databases, evaluation of clinical decision support tools and developing an evidence-based clinical informatics service.

It has become readily apparent in many organisations, particularly those that include substantive research as a major component of their activity such as research/university hospitals and academic medical centres, the skills required to fulfil all aspects of the extended role required of the $\mathrm{CClO}$ are not possessed by one individual, and significant time commitments are required to both aspects. Research focus requires a different set of core skills, including a deeper, granular, understanding of research methodology, study design, data syntax and research and data governance.

The role of the CRIO has therefore begun to emerge, who roles include design and optimisation of clinical systems and platforms to support research data acquisition, facilitation of 
embedding research into clinical care, application of research methodology to all data sources to improve operational delivery and optimisation of clinical care, optimisation of secondary use of EHR data and aspects of research data governance, compliance and links to academia. Furthermore, the CRIO provides senior leadership for the clinical informatics strategy for the organisation, in terms of linking with university expertise, collaboration and training and supervision of junior staff in informatics. This CRIO role is presently less well-defined than the $\mathrm{CCIO}$, but should similarly be an experienced clinician but one with extensive research experience in addition to knowledge of clinical and research ICT systems, data architecture and data governance.

This new role of $\mathrm{CRIO}$, as part of the $\mathrm{CIO}$ and $\mathrm{CCIO}$ team, is now becoming recognised. ${ }^{9}$ The CRIO role therefore complements and supports the roles and responsibilities of the $\mathrm{ClO}$ and $\mathrm{CClO}$; together all three should act synergistically towards a common goal of optimising healthcare delivery through the use of technology and data driven insights. In this way, the team can adequately have oversight of all ICT related issues across the organisation, the $\mathrm{ClO}$ from a technical, political and operational perspective, the $\mathrm{CClO}$ from the perspective of clinical care, pathways and patient experience, and the CRIO from the perspective of optimising digital health systems for research use and ensuring that data are collected and used to maximise benefit.

\section{DISCUSSION}

\section{C-team evolution}

The 'three Cs' team have a range of roles including early adoption and championing of new technology, through research activity, expertise with applied systems and organisation wide change management tasks including staff engagement and transformation. The requirements of these clinical informatics roles are beginning to be recognised by organisations, for example, the American Medical Informatics Association provides guidance regarding proposed $\mathrm{CCIO}$ knowledge, education, skillsets and operational scope, emphasising that these roles are evolving with need for future workforce training and education. ${ }^{8}$

The history of the $\mathrm{CClO}$ is well described. The term was first formally defined by healthcare recruiters around 20 years ago being a senior physician leader in health IT. ${ }^{10}$ However, only around a third of $\mathrm{ClOs}$ employed Chief Medical Information Officers a decade ago, increasing to around three quarters by 2012. $5,8,11,12$ Analogous to $\mathrm{ClOs}, \mathrm{CClO}$ are starting to establish both formal and informal networks pooling knowledge and sharing experiences. Such networks are invaluable in helping the $\mathrm{CClO}$ develop their skills and knowledge by tapping into other individuals that are established in the role. A similar network of support and capability does not yet exist for CRIO's, although it is likely that this will develop.

The CRIO role at present remains less well established but with increasing recognition of its importance and function. Job descriptions from selected US institutions, ${ }^{13-15}$ include functions such as:

- directing and overseeing research informatics activities across the organisation (which may or may not include acting as Director of a 'Centre' for informatics)

- coordinating clinical research informatics activities between academic and clinical components

- ensuring that clinical informatics systems support research objectives, including aspects of research data governance

- support for researchers to translate their needs into technical designs and informatics solutions

- connecting faculty with clinical data to advance biomedical research

- identifying and leading innovations in research IT and research informatics

As clinical experience and an on-going practice are recommended for successful delivery of the $\mathrm{CClO}$ role, it is emphasised that the CRIO role is also a senior leadership position such that CRIOs should ideally be established academics with experience in biomedical informatics, biomedical research, electronic health records, clinical data warehousing, clinical medicine, scholarly publication and presentation, research governance and attracting research funding and academic teaching.

The emerging role of the CRIO is thus becoming increasingly recognised internationally with the general moves towards more data-intensive healthcare and research. ${ }^{9}$ A recent survey in the United States reported that CRIOs come from a range of academic backgrounds, with varied experience in biomedical informatics. In this study, ensuring adequate funding, issues around data governance and advancing data analytics were described as the major challenges they faced. ${ }^{9}$

The CRIO should work with the $\mathrm{CCIO}$ and $\mathrm{CIO}$ in developing and evaluating the various forms of technology which may impact clinical care, such as clinical decision support, which will be increasingly used. The CRIO should bring academic method and rigour to develop and evaluate such systems, whilst the $\mathrm{CCIO}$ should determine how decision support tools are best used in clinical pathways and evaluate their uptake and utility in practice. The $\mathrm{CIO}$ retains oversight of all ICT developments and strategies and is primarily responsible for the information infrastructure, organisational procedures and overall strategy relating to all information systems. For example, as part of a recent large procurement process for an electronic patient record system at our centre, evaluation of a complementary research and analytics platform required experience of use of 'real-world' health data for academic purposes in addition to an understanding of data analytic tools and components, which could be provided by the $\mathrm{CRIO}$, but in the context of the wider $\mathrm{CIO}$ team, to ensure an appropriate solution aligned with the wider programme.

In the UK, very few formal CRIO roles currently exist but based on international experience, and several recent government documents emphasising the importance of digital health for future research, this is likely to change and there is now both an opportunity and need to formalise the optimal composition and requirements of the ' $\mathrm{C}$ ' team for academic 
healthcare institutions based on this emerging model. ${ }^{16,17}$ This is likely to be of particular importance with recognition of the increasing need for expertise in aspects of data governance for research use, especially in light of current developments such as the UK National consultation on use of data and consent, and the impact of the General Data Protection Regulations on medical research. These complimentary but

\section{REFERENCES}

1. Krinsky ML. The chief information officer-capturing healthcare's rare bird. Computers in Healthcare 1986;7(8):66. PMid: 10277450.

2. Bell R, Malec BT. The CIO's (chief information officer) location in the organizational structure: implications for health administration education. The Journal of Health Administration Education 1990;8(1):25-35. PMid: 10103710.

3. Glaser JP. The role of the chief information officer in the health care organization in the 1990s. Topics in Health Information Management 1993;13(3):62-8. PMid: 10124873.

4. NHS England. Senior appointments announced to drive NHS technology and information modernisation [Internet]. Available from: https://www.england.nhs.uk/2016/07/senior-appointments/. Accessed 15 October 2017.

5. Kannry J, Fridsma D. The Chief Clinical Informatics Officer (CCIO). Journal of the American Medical Informatics Association 2016;23(2):435. Available from: https://doi.org/10.1093/jamia/ ocw034. PMid: 26961494.

6. Wachter RM. Making IT work: harnessing the power of health information technology to improve care in England-executive summary. Available from: https://www.gov.uk/government/ uploads/system/uploads/attachment_data/file/550899/Watcher_ Exec_Summary_Accessible.pdf. Accessed 15 October 2017.

7. NHS England. NHS Digital Academy [Internet]. Available from: https://www.england.nhs.uk/digitaltechnology/info-revolution/ nhs-digital-academy/. Accessed 15 October 2017.

8. Kannry J, Sengstack P, Thyvalikakath TP, Poikonen J, Middleton B, Payne T, et al. The Chief Clinical Informatics Officer (CCIO): AMIA task force report on CCIO knowledge, education, and skillset requirements. Applied Clinical Informatics 2016;7(1):143-76. Available from: https://doi.org/10.4338/ACl-2015-12-R-0174. PMid: 27081413; PMCid: PMC4817341.

9. Sanchez-Pinto LN, Mosa ASM, Fultz-Hollis K, Tachinardi U, Barnett WK, Embi PJ. The emerging role of the Chief Research Informatics Officer in Academic Health Centers. Applied Clinical synergistic roles will therefore be essential for the future successful creation of digital research hospitals.

\section{Acknowledgements}

NJS is supported by awards from Great Ormond Street Hospital Childrens Charity, an NIHR Senior Investigator Award and the NIHR GOSH Biomedical Research Centre.

Informatics 2017;8(3):845-53. Available from: https://doi. org/10.4338/ACl-2017-04-RA-0062. PMid: 28832068.

10. Leviss J, Kremsdorf R, Mohaideen MF. The CMIO-A new leader for health systems. Journal of the American Medical Informatics Association 2006;13(5):573-8. Available from: https://doi.org/10.1197/jamia.M2097. PMid: 16799119. PMCid: PMC1561791.

11. Mckinney M. CMIOs steadily on the rise. Hospitals \& Health Networks 2010;84(3):41-2.

12. Hagland M. Ramping up to leadership CMIOs' profile keeps growing. CMIOs take on new responsibilities as patient care organizations move through the quality journey [Internet]. Healthcare Informatics 2012;29(4):10-2, 4, 6. Available from: http://www.ncbi.nlm.nih.gov/pubmed/22574397.

13. Office of the Chief Research Informatics Officer (CRIO). Official website for the Chief Research Informatics Officer, University of Chicago, Biological Sciences Division [Internet]. Available from: http://crio.uchicago.edu/. Accessed 15 October 2017.

14. Penn Institute for Biomedical Informatics. IBI is Recruiting a Chief Research Information Officer (CRIO) [Internet]. Available from: http://upibi.org/ibi-is-recruiting-a-chief-research-information-officer-crio/. Accessed 15 October 2017.

15. Seattle Children's Research Institute Appoints Chief Research Information Officer. Seattle Children's Hospital [Internet]. Available from: http://www.seattlechildrens.org/media/press-releases/2014/ seattle-childrens-research-institute-appoints-chief-research-information-officer/. Accessed 15 October 2017.

16. Five year forward view. 2014. Available from: https://www.england.nhs.uk/wp-content/uploads/2014/10/5yfv-web.pdf. Accessed 15 October 2017.

17. Accelerated Access Review: Final Report Review of innovative medicines and medical technologies. 2016. Available from: https://www.gov.uk/government/uploads/system/uploads/attachment_data/file/565072/AAR_final.pdf. Accessed 15 October 2017. 